\title{
Effects of silica sol on boric-sulfuric acid anodic oxidation of Al alloy
}

\author{
Xiaoyu Yang ${ }^{1, a^{*},}, \mathrm{Hu} \mathrm{Wei}^{2, b}$ \\ ${ }^{1}$ Hunan Chemical Industry Profession and Technology College, Zhuzhou 412004, China \\ ${ }^{2}$ Army Aviation Institute of PLA, Beijing 100123, China \\ ayangxy_110@163.com, bhuweiqcsj@163.com \\ * the corresponding author
}

Keywords: silica sol; boric-sulfuric acid anodic oxidation; Al alloy

Abstract. Al alloy anodized coating was prepared in boric-sulfuric acid with the addition of silica sol or not. The current and voltage transients of the anodizing process were collected by ZF-10B data collection instrument. The corrosion resistance was examined by neutral salt spray, electrochemical impedance spectroscopy (EIS) test and titrating test, respectively. Results showed that the addition of silica sol did not change weight, thickness and composition of the anodized coating significantly. However, the uniformity, fineness and surface morphology of the coating were improved. Moreover, corrosion resistance of the anodized coating was increased with the addition of silica sol. Meanwhile, it showed that nearly no damage on the fatigue properties of $\mathrm{Al}$ alloy substrate as compared with chromic acid anodizing and boric-sulfuric acid anodizing.

\section{Introduction}

Not only has $\mathrm{Al}$ alloy been primary choice for structural component of aircrafts for year but also it is used widely in other field like automotive industry and so on, due to its excellent mechanical and processing properties such as high specific strength and fatigue resistance[1,2]. However, $\mathrm{Al}$ alloy degrade under harsh corrosive conditions. The mechanism of pitting corrosion on surface of $\mathrm{Al}$ alloy has been investigated and it is suggested that corrosion resistance of $\mathrm{Al}$ alloy could be improved by anodic oxide films significantly $[3,4]$. Chromic acid anodizing processing has been employed to provide optimal protection for $\mathrm{Al}$ alloy for years. But this technology is quite disputable because highly toxic and environmentally hazardous $\mathrm{Cr}^{6+}$ ions are produced during the process. Therefore, various kinds of alternative methods have been developed such as boric-sulfuric acid anodizing[5,6]. The coatings prepared in boric-sulfuric acid exhibit uniformly good corrosion resistance while bring about almost no unfavourable effect on fatigue property of the alloy substrate. However, it is still not as reliable as chromate so that some studies were undertaken to improve the process.[7]. A number of modification for the standard boric-sulfuric acid anodizing process have been employed, for example, addition of phosphoric acid, borate and corrosion inhibitors such as cerium IV and molybdate ions and so on into the anodizing solution[8,9].

With good chemical stability and environmental friendliness, silica sol is widely used as metal oxide coatings or organic-inorganic hybrid sol-gel coatings for metal materials. Silica sol is also used as sealing in Al alloy anodizing post-processing[10,11]. What's more, silica sol or other kinds of sol was used to modify base electrolytes in magnesium or $\mathrm{Al}$ alloy oxidation and micro-arc oxidation. It has been reported that with the addition of silica sol into the anodizing electrolytes, the growth rate of coatings increased so that corrosion resistance was improved [12-14].

Although the standard boric-sulfuric acid anodic oxidation using in aerospace is carried out under a relatively lower voltage in alkaline electrolytes as compared with above mentioned researches, silica sol modified electrolytes may provide better performance than that of chromic acid anodizing. In this paper, experiments were carried out to evaluate behavior of the $\mathrm{Al}$ alloy anodized in boric-sulfuric acid with or without the addition of silica sol. Furthermore, various tests were designed to assess the uniformity, fineness and corrosion resistance of the anodized coatings. 


\section{Experimental}

Preparation of Anodized Coatings. Specimens were cut from $\mathrm{Al}$ alloy sheets into dimension of 100 $\mathrm{mm} \times 20 \mathrm{~mm} \times 1.3 \mathrm{~mm}$. In electrochemical tests, components of the device and specimen were connected by aluminum wire. Alkali silica sol with an average grain size of $4 \sim 5 \mathrm{~nm}$ and $\mathrm{pH}$ value of 8.5 9.0 was used in this paper. The specimens were immersed into a mixture comprising of $\mathrm{NaOH} 160$ $\mathrm{g} / \mathrm{L}, \mathrm{Na}_{2} \mathrm{~S} 55 \mathrm{~g} / \mathrm{L}$, and triethanolamine (TEA) $45 \mathrm{ml} / \mathrm{L}$ for $1 \sim 3 \mathrm{~min}$ at $90 \sim 100^{\circ} \mathrm{C}$ to remove the dural alclad on $\mathrm{Al}$ alloy. After that, specimens were washed with de-ionized water and then dried in a hot wind oven. Before anodizing, specimens were immersed successively in $40 \mathrm{~g} / \mathrm{L} \mathrm{NaOH}$ solution for 1 2 minutes, de-ionized water, $30 \mathrm{wt} \% \mathrm{HNO}_{3}$ solution for 20 30 seconds, de-ionized water, redistilled water. After that, specimens were anodized immediately. concentration of $\mathrm{H}_{2} \mathrm{SO}_{4}$ and $\mathrm{H}_{3} \mathrm{BO}_{3}$ was determined to be $45 \mathrm{~g} / \mathrm{L}$ and $8 \mathrm{~g} / \mathrm{L}$ according to a Boeing patent [15] while the concentration of silica sol was set at $20 \mathrm{vol} . \%$. Lead sheet was used as the cathode and area ratio of cathode to anode was about 2:1. The anodic coating was prepared at $(25 \pm 0.5){ }^{\circ} \mathrm{C}, 15 \mathrm{~V}$ without other declaration. And anodizing voltage was raised by $5 \mathrm{~V} / \mathrm{min}$. After anodizing, the specimens used for corrosion resistance tests were sealed in redistilled water at $100^{\circ} \mathrm{C}$ for $20 \mathrm{~min}$, while the ones for other tests were not sealed.

\section{Characterization of Coatings.}

Color and Appearance. Color and appearance of the anodized coatings were visually observed.

Electric Resistance. Electric resistance between any two points on the coating was tested by AVO meter to evaluate the uniformity and integrity of the anodized coatings, and the test was conducted at least five times for each specimen. ZF-10B data collection instrument was used to detect the change of anodic current or voltage during the anodizing for current or voltage transients versus time patterns. A constant current $(0.3 \mathrm{~A})$ process and a constant voltage $(15 \mathrm{~V})$ process were applied separately for the patterns. Weight of anodized coating was measured based on standard ASTM B137, and the test area of specimens was about 3600 millimeter square without sealing.

Fatigue Testing. The fatigue testing specimens were prepared according to ASTM E466 and polished by emery paper followed by buffing. The testing was conducted on Instron 8871 fatigue testing machine with a frequency of $10 \mathrm{~Hz}$ and a load ratio of $\mathrm{R}=0.1$ while maximum stress was set as $300 \mathrm{MPa}$.

\section{Results and Discussion}

The anodized coatings formed in aqueous solution of sulfuric and boric acids with or without silica sol are all colorless and thus the specimens are silver white as the alloy substrates. Electric resistance values between any two points of the coatings all exceed $200 \mathrm{M} \Omega$, which indicates that all the anodized coatings are uniform and integrated ones. The current transients at constant voltage during anodizing process of $\mathrm{Al}$ alloy in four electrolytes are shown in Fig.1. In which, three electrolytes were added $10 \mathrm{wt} \%, 20 \mathrm{wt} \%$ and $30 \mathrm{wt} \%$ silica sol respectively. In the electrolytes with or without silica sol, the current transients show the same trend. They decrease quickly from quite large values to minimum in the first 20 seconds and then increase abruptly again for another 30 seconds. After reaching maximum value, the current transients decreased slightly again. Although the trend is the same, the minimum and maximum current values are different. Electrolytes with silica sol added has larger current fall of about $0.05 \mathrm{~V}$. This value may be related to the barrier layer of the anodic film. When the anodic film formed on the surface of $\mathrm{Al}$ alloy, the barrier layer grew promptly at first, followed by the porous layer. The barrier layer consists of non-conductive alumina and the processing is under a constant voltage. As a result, the current fall significantly at the beginning. A rapid current drop means larger electric resistance of the barrier layer, so that the base material gets better protection from the anodic film. Moreover, the final current is larger in the electrolyte contained silica sol, which indicates that silica sol particles may change the reaction process on the inter-surface between the alloy sheet and the electrolyte so as to improve the growth rate of the anodic film. 


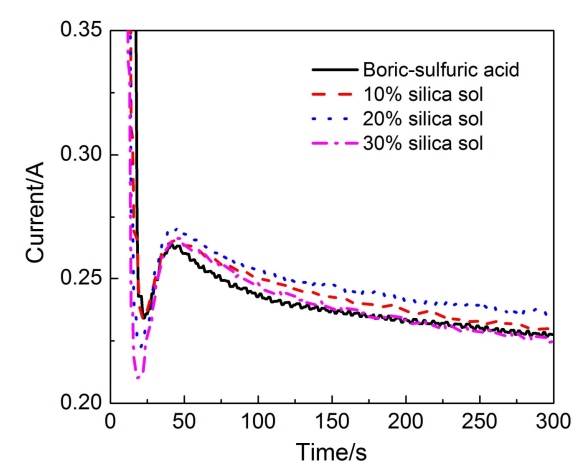

Fig.1 Current transients versus time patterns of $\mathrm{Al}$ alloy during anodizing in different electrolytes

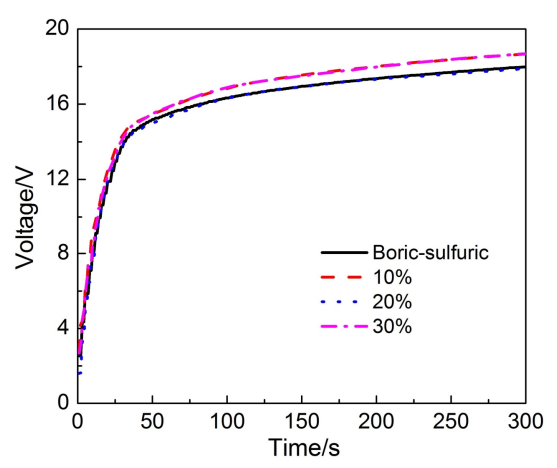

Fig. 2 Voltage transients-time performance of $\mathrm{Al}$ alloy in electrolytes with and without silica sol

In addition, Fig. 2 shows the voltage transients at constant current during anodizing process of $\mathrm{Al}$ alloy in four electrolytes, in which, three electrolytes were added $10 \mathrm{wt} \%$, 20wt $\%$ and 30wt $\%$ silica sol respectively. The trend of voltage is also the same as coatings prepared in different electrolytes, and both of them increase promptly during the first 30 seconds.

Furthermore, the electrochemical impedance spectroscopy (EIS) loops of Al alloy anodizing coatings in different electrolytes are shown in Fig.3. It is well known that diameter of the loops is positively correlated to the polarization resistance of the specimens, therefore, it is inferred obviously from Fig. 3 that the coating formed in the solution containing silica sol exhibited higher corrosion resistance.

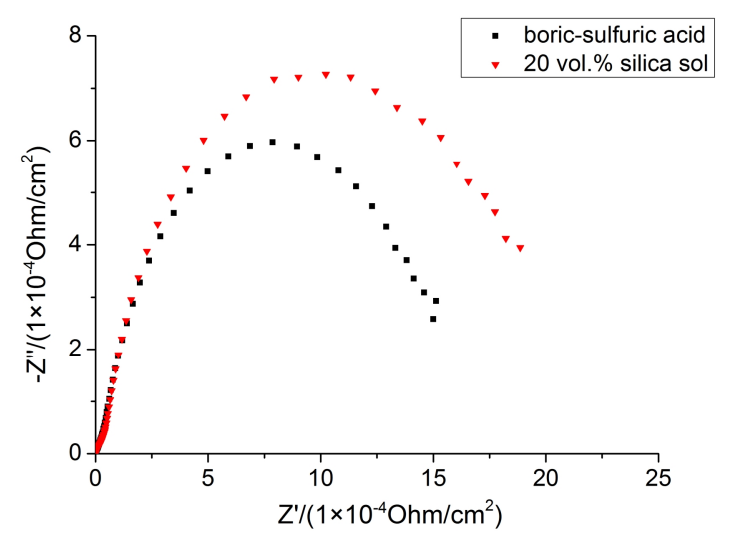

Fig.3 Electrochemical impedance spectroscopy (EIS) spectrum of $\mathrm{Al}$ alloy anodizing coating in different electrolytes

The fatigue property test results are shown in Table 1, in which chromic acid anodizing coating has been prepared for comparison. The specimens were anodized in an electrolyte consist of $45 \mathrm{~g} / \mathrm{L} \mathrm{CrO}_{3}$ under $35^{\circ} \mathrm{C}$ for $30 \mathrm{~min}$ followed by sealing in a solution of $\mathrm{CrO}_{3} 70 \mathrm{mg} / \mathrm{L}$ and $\mathrm{Na}_{2} \mathrm{Cr}_{2} \mathrm{O}_{7} 48 \mathrm{mg} / \mathrm{L}$ under $100^{\circ} \mathrm{C}$ for $20 \mathrm{~min}$. After that, the bare specimens were successively cleaned in $40 \mathrm{~g} / \mathrm{L} \mathrm{NaOH}$ solution for 1 2 minutes, de-ionized water, $30 \% \mathrm{HNO}_{3}$ solution for 20 30 seconds, de-ionized water, and redistilled water before fatigue test. Results showed that after anodizing, although the fatigue life for all specimens were shorter than the substrate, specimens anodized in boric-sulfuric containing silica sol or not all behaved longer fatigue life than that anodized in chromic acid . 
Table 1. Fatigue life of specimens prepared in different electrolytes under the same stress level

\begin{tabular}{ccccc}
\hline electrolytes & bare & chromic acid & boric-sulfuric acid & silica sol addition \\
\hline No. 1 & 80204 & 74445 & $/$ & 87139 \\
No. 2 & 86633 & 88709 & 79588 & 82823 \\
No. 3 & 83402 & 71793 & 77290 & 72902 \\
No. 4 & $/$ & 82032 & 58837 & 71844 \\
No. 5 & $/$ & 67427 & $/$ & 63616 \\
median fatigue life & 83371 & 76514 & 71264 & 75199 \\
Compared with bare & $/$ & 0.917 & 0.855 & 0.902 \\
\hline
\end{tabular}

According to all the results above, there is no significant change in the composition and weight of the coating which could be ascribed to the thickness of the coating. The thickness is controlled to be around $2 \sim 3 \mu \mathrm{m}$ in order to avoid serious mechanical damage to the $\mathrm{Al}$ alloy substrate. Therefore, the change of coating weight could not be observed. However, the surface and cross section morphology turn out to be better for samples anodized in boric-sulfuric acid containing silica sol. Furthermore, the corrosion resistant is improved for samples as well. Consequently, it is assumed that silica sol particles may be adsorbed on the surface of $\mathrm{Al}$ alloy substrate during anodizing, which plays a role in changing the mechanism of anode oxidation reaction which is advantageous to form oxide coatings with better properties.

\section{Summary}

Silica sol of different volume fraction was added directly into standard Al alloy boric-sulfuric acid anodizing electrolyte. The results showed that addition of silica sol cannot change weight, thickness and composition of the anodizing coatings significantly. However, silica sol could indeed improve the microstructure and surface morphology of the coating. As a result, the corrosion resistance of standard boric-sulfuric acid anodizing coating is improved. Moreover, there is nearly no damage on the fatigue properties when compared with chromic acid anodizing.

\section{Acknowledgements}

This work was financially supported by the Fundamental Research Funds for the Central Universities (YWF-11-03-Q-001), the Fundamental Research Funds for the Universities of Hunan Province (11C0465) and the Science Foundation of the Science and Technology Department of Hunan Province (2012SK3180).

\section{References}

[1] E.A. Starke Jr, J.T. Staley, Application of modern Al alloys to aircraft, Progress in Aerospace Sciences, 32 (1996) 131-172.

[2] G. Thompson, P. Skeldon, X. Zhou, K. Shimizu, H. Habazaki, C. Smith, Improving the performance of aerospace alloys, Aircraft Engineering and Aerospace Technology, 75 (2003) 372-379.

[3] Z. Szklarska-Smialowska, Pitting corrosion of aluminum, Corrosion Science, 41 (1999) 1743-1767.

[4] C.J. Smith, Advances in protective coatings and processes for aerospace applications, Aircraft Engineering and Aerospace Technology, 67 (1995) 13-16. 
[5] S.J. Garcia-Vergara, P. Skeldon, G.E. Thompson, H. Habazaki, A tracer investigation of chromic acid anodizing of aluminium, Surface and Interface Analysis, 39 (2007) 860-864.

[6] R.L. Twite, G.P. Bierwagen, Review of alternatives to chromate for corrosion protection of aluminum aerospace alloys, Progress in Organic Coatings, 33 (1998) 91-100.

[7] G. Thompson, L. Zhang, C. Smith, P. Skeldon, Boric/sulfuric acid anodizing of Al alloys 2024 and 7075: film growth and corrosion resistance, Corrosion, 55 (1999) 1052-1061.

[8] L. Domingues, J.C.S. Fernandes, M. Da Cunha Belo, M.G.S. Ferreira, L. Guerra-Rosa, Anodising of Al 2024-T3 in a modified sulphuric acid/boric acid bath for aeronautical applications, Corrosion Science, 45 (2003) 149-160.

[9] M. Saeedikhani, M. Javidi, A. Yazdani, Anodizing of 2024-T3 Al alloy in sulfuric-boric-phosphoric acids and its corrosion behavior, Transactions of Nonferrous Metals Society of China, 23 (2013)

2551-2559.

[10] A.S. Hamdy, D.P. Butt, Environmentally compliant silica conversion coatings prepared by sol-gel method for Al alloys, Surface and Coatings Technology, 201 (2006) 401-407.

[11] M. Zemanová, M. Chovancová, Sol-gel method for sealing anodized aluminum, Metal Finishing, 101 (2003) 14-16.

[12] M. Tang, W. Li, H. Liu, L. Zhu, Influence of titania sol in the electrolyte on characteristics of the microarc oxidation coating formed on 2A70 Al alloy, Surface and Coatings Technology, 205 (2011) 4135-4140.

[13] W. Li, L. Zhu, Y. Li, Electrochemical oxidation characteristic of AZ91D magnesium alloy under the action of silica sol, Surface and Coatings Technology, 201 (2006) 1085-1092.

[14] L. Zhu, Y. Li, W. Li, Influence of silica sol particle behavior on the magnesium anodizing process with different anions addition, Surface and Coatings Technology, 202 (2008) 5853-5857.

[15] C. Wong, Y. Moji, Method for anodizing aluminum, in: T.B. Company (Ed.), 1990. 